\title{
RESEARCH PAPER \\ TECHNICAL LIMITATIONS OF AFRICAN PRINTS AND THEIR IMPLICATIONS ON GARMENT CONSTRUCTION IN GHANA
}

\author{
A.M. Amankwah and E. K. Howard \\ Department of Industrial Art, College of Art and Social Sciences, KNUST, Ghana
}

\begin{abstract}
African Prints are major raw materials for the Clothing Industry in Ghana. Garment manufacture requires the consideration of technical factors such as alignment of prints to the fabric grain line, standard fabric width, appropriate motif placement/arrangement and repeat pattern among others. As a qualitative enquiry, the study employs descriptive observational research design with observation and interview as the main data collection instruments. The analysis of the study revealed that due to lack of collaboration between the textile and fashion industries, most African prints on the market do not possess the requisite technicalities but rather show weak spots such as limited fabric width, predominant use of full and half-drop pattern layouts, large motifs with intricate textures that pose a greater challenge to the garment designer. Moreover, it was apparent that most local print designs do not follow lengthwise grain of fabric although the grain line is a very important technical consideration in garment construction. The prints, on the other hand, are packaged in six or twelve yards implying that getting the required width will necessitate joining pieces together which is not convenient and amount to a lot of waste during garment construction. The study, among other things, recommends a strong collaboration between textile and fashion designers to ensure that all necessary technical requirements in garment construction are met in the textile design process in order for the two parties to work effectively to meet international standards.
\end{abstract}

Keywords: Mummy cloths, Garment, Construction, Technicalities

\section{INTRODUCTION}

It has been observed that, most of the countries considered as economic giants in the world largely depend on textiles and garment production for the sustainability and development of other sectors. These countries include China, the United State, India and Pakistan. The production and trade activities of the textiles and clothing industries have long been a catalyst of economic growth throughout the world. In 2001 , the sector accounted for over US $\$ 450$ billion of trade worldwide. In the European Union alone, the sector employees are over 2.1 million with annual sales of 200 billion Euros, and its exports represent 45 billion Euros, making it the world's second largest exporters after 
China (WTO, 2004). These achievements have been made possible through strong collaborations or interdependency that exists between the Textiles and Fashion industries.

The African and for that matter the Ghanaian identity is more often than not, captured in the traditional clothing in the form of symbolic woven kente cloths and printed fabrics. For the purpose of this study, the focus will be on the printed African fabrics also known as "mummy cloths".

\section{African Prints (Mummy Cloths) \\ The advent of "mummy cloth" in Ghana could be traced back to the colonial period during the Gold Coast era. The cloths were first brought into Ghana by some Ashanti soldiers who were then serving in the Dutch army in some colo- nies in Indonesia. These soldiers were given to the Dutch commissioner as slaves due to the cordial relationship that existed between the then Asantehene and the Dutch commissioner.}

The soldiers, who were attracted to the aesthetic qualities of the Javanese prints, brought samples of the cloths to Gold Coast after their service. The Gold Coast women upon seeing the cloths became very fascinated about them and established trade links between Indonesia and the Gold Coast upon which large quantities were brought to the Gold Coast (Osei-Bonsu, 2001).The prints come with very interesting African motifs based on proverbs, adages, royal emblems, adinkra symbols among others. The choice of motif, composition, repeats etc. are carefully executed making them look very attractive when displayed. Moreover, the prints bear philosophical significance. They have names that depict or explain the beliefs and practices of the Ghanaian culture. Notable ones include "Akyekyedeeakyi"-the back of the tortoise, "Fathia fata Nkrumah"-Fathia deserves Nkrumah among others (Orhin, 2007).

Ultimately, the producers of these prints look forward to the products being bought, sewn and worn with maximum impact to capture the es- sence of the design so as to generate sales. For a garment to be worn with maximum impact, it demands that, some technicalities must be followed in the construction of the garment. These technicalities are either ignored or fabric designers are not exposed to them thereby creating technical difficulties during garment manufacture. It could be argued that, the garment designer/manufacturer who intends to construct the fabric into garment must wield the necessary skills to work around the difficulties posed by the fabric in use. But, some fundamental technical considerations cannot be corrected by any act of magic. It is obvious that these African print designers view their work as an art piece without taking into consideration how the beautiful pieces of fabrics they produce are translated into garments.

Technical Factors in Garment Construction

Certain parameters are considered very paramount and perhaps indispensable in selecting printed textiles for garment construction. These include the grain line, motif arrangement, and fabric width among others.

The grain line: The fabric grain is the direction of the woven fabric parallel to the selvedge and the long warp threads. Prints follow the fabric grain. Most fabrics have warp threads being stronger and of high tension than the weft threads and therefore it is less likely for a garment to shrink in length (Jenkyn, 2005). In such instances, pattern pieces are placed on the warp grain to avoid swatting at the seat, elbow and knees. A fabric cut on the grain creates a balance for the garment to hang straight. This implies that off-grain garments do not hang properly, hence causing drapery defects in the resultant garment.

Motif arrangement/repeat pattern: There is no hard and fast rule about which motif could best be repeated. However, when designing a print for specific garment, you need to consider the cut of the fabric. A one-way print where motifs are aligned in one direction has less cutting flexibility than all-ways prints. It could be 
observed that some motifs when cut through become highly impossible to even creatively join together without marring the beauty of the fabric. All-ways prints are preferred choices in most cases rather than one-way designs. Oneway designs are less economical as they require more fabric to align the prints during garment construction (Tatham and Seaman, 2003).

Apart from the one-way designs being less economical, working with such fabrics is time consuming since great care has to be taken in aligning the prints. One-way prints are economically viable especially in made - to - measure garments. In this case, the more time spent on making the garment the higher the creativity and cost of the product.

Jenkyn (2005) is of the view that time is a crucial issue in today's global marketplace. There is a high demand for new fashion such that it must be brought to the market fast or perish. Lead times have considerably reduced especially in mass produced garments. Any constraints, for instance time spent on laying and cutting of fabrics that hamper quick delivery of goods to the stores must be addressed. Clothing manufacturers must respond with speed, quality and technological organisation and fabric designers cannot afford to be less concerned.

Fabric Width: The width of the fabric is the distance across the fabric perpendicular to the selvedge excluding the selvedge on woven goods. Widths are quoted in two numbers to allow for the variance, i.e. $35 / 36$ inches or $58 / 60$ inches. Fabrics manufactured in the United State and Asia are measured in inches, whiles fabrics from Europe and elsewhere in the world are measured in centimetres. Traditionally, wide fabrics are knitted or woven in the following widths; 36 inches $/ 90 \mathrm{~cm}$, 45 inches $/ 115 \mathrm{~cm}, 60$ inches $/ 150 \mathrm{~cm}$, $72 \mathrm{inches} / 180 \mathrm{~cm}$ or $120 \mathrm{inches} / 300 \mathrm{~cm}$.

Occasionally, one could find fabric in $27 \mathrm{inches} / 70 \mathrm{~cm}, \quad 392 \mathrm{inches} / 100 \mathrm{~cm}$, 54 inches $/ 140 \mathrm{~cm}$ or 66 inches $/ 165 \mathrm{~cm}$ (Fabric
Width, 2009).

The fabric is best put to use when wider widths are employed. The wider the fabric width, the better utilisation one gets. Conveniently, 60 inches width goods are the most desirable for cost effectiveness in garment manufacture. One will obviously need more yards of 36 inches wide fabric per garment than you would need to make the same in 60 inches wide fabric. These are technical parameters that garment manufacturers consider very pertinent in their work.

Fabric designers should take note and factor these parameters in the fabrics they design for the garment industry.

\section{METHODOLOGY}

The study aims at giving the much needed highlight on some vital technical issues that fabric designers cannot take for granted if they want garment manufacturers to create designs with maximum impact to increase sales for mutual benefits. As a qualitative enquiry, the study employs mainly descriptive observational study with observation and interview as the main data collection instrument. Research questions for which answers were sought through the collection and analysis of data were as follows:

- What technicalities govern garment construction?

- What features characterize African print designs?

- What limitations do African prints pose in garment construction?

\section{Population and Product Sampling}

The sampling frame of the study comprises printed textiles of TexStyles Ghana Limited (TGL), Akosombo Textile Limited (ATL) and selected freelance textile and fashion designers in Ghana. The purposive sampling technique was used to select resourceful respondents from the sampling frame for the study.

Five textile designers in the country's major textile factories with specific reference to Tex- 
Style Ghana Limited and Akosombo Textile Limited (three respondents from TGL and two from ATL), together with five selected freelance fashion designers from Accra and Kumasi (two from Kumasi and three from Accra) were interviewed to solicit their views on the design and subsequent use of African prints in garment construction. Their products were also observed to authenticate their views. A market survey was embarked upon by the research team to critically observe and examine the various local prints to obtain first-hand information for the study.

Twenty selected tailors and dressmakers in Accra and Kumasi were randomly selected and observed to find out the challenges the designers face with regards to working with African prints and how they manage to work to satisfy customer needs. Out of the twenty, five were tailors and fifteen were dressmakers with two tailors and ten dressmakers from Kumasi and three tailors and five dressmakers from Accra. Three of the tailors were Polytechnic graduates and the other two learnt to sew through apprenticeship. For the dressmakers, five were Polytechnic graduates and ten learnt to sew through apprenticeship.

\section{RESULTS}

Among the major Textile industries in Ghana are Texstyles Ghana Limited (TGL), formally Ghana Textile Printing Company (GTP) and Akosombo Textile Limited (ATL) situated in Tema and Akosombo respectively. The core business of both companies is the production of wax prints mainly for the Ghanaian market as well as some countries in West Africa and parts of Asia and Europe. Wax block prints are consumed in West and Central Africa, from Senegal through the coastal areas of Ivory Coast, Ghana and Nigeria, towards the southern African areas like Congo - Brazzaville and CongoKinshasa (Vlisco, 2011).Texstyle Ghana Limited (TGL) does not sell outside the African market but the parent company Vlisco sells in Asia and the Caribbean. Apart from wax prints, the companies also deal in fancy prints.

\section{Fabric Grain}

Through observation it was revealed that the issue of prints not following the lengthwise grain has to do more with the wax prints. It was apparent that, the designers of both companies, Akosombo Textile Limited and Texstyle Ghana Limited viewed their works as art pieces and also as raw materials for the Fashion industry in Ghana. Even though they see it as raw material for the Fashion Industry, consideration is not given to the technicalities pertaining to garment manufacture and therefore no attempt is made to design fabrics that address such issues like conformity of design to fabric grain, applying the standard acceptable fabric width, proper motif placement or layout etc. It is worth noting that Fabric designers of these companies are more inclined to textile design with little or no knowledge of how the fabrics they design are translated into garments. This is mainly due to the fact that Texstyle Ghana Limited, Akosombo Textile Limited and garment manufacturers in Ghana, operate independently with no form of collaboration. Texstyle Ghana Limited has in the past, liaised and continues to liaise with some notable fashion designers especially Kofi Ansah to get feedbacks on the use of its printed textiles but the results of such collaborations have made little impact on the design process of the company.

The reasons assigned to why prints do not follow the grain were that, designing to follow the lengthwise grain has not been given thoughtful consideration. Though some designs follow the grain naturally, there is no deliberate attempt to align designs to follow the grain. Another reason has to do with the issue of presentation. The design staff of Texstyle Ghana Limited and Akosombo Textile Limited explained that printed fabrics were exhibited or presented to follow the width of the fabric and not the length. Therefore aligning prints to follow the lengthwise grain will distort the designs during presentation. Designs then become unreadable if prints follow the lengthwise grain and for that matter showcased or presented along the width of the fabric. 
Moreover, the dimensions of the rotary screens, i.e. $91.5 \mathrm{~cm}$ and $64.2 \mathrm{~cm}$, pose a great limitation on the design in terms of its alignment to the lengthwise grain of the fabric. Repeats are made to meet the circumference of the rotary screen. The respondents, arguably, opined that designing along the length of the fabric is impossible because repeats become infinite, making it difficult to print. However, if clients bring paper designs that follow the lengthwise grain such designs are printed. This establishes that, printing of such designs is possible. It was evident that Texstyle Ghana Limited had printed designs that follow the lengthwise grain for clients like Vodafone, a communication company, and a seasoned Fashion Designer, Kofi Ansah. These clients brought their own designs made in the lengthwise grain format to be printed to meet their specifications. It is obvious that the designers who made the paper designs for Vodafone Ghana and Kofi Ansah understand the principle of the fabric grain in clothing construction.

In addition, the fabric designers explained that the designs produced by the textile companies are multipurpose. Consumers use the fabric as wrap (chiton), a simple rectangle of fabric wrapped around the body leaving the right hand bare or fastened on both shoulders. It is also used as chlamys (for men) usually fastened on one shoulder and the female form known as the peplos (Laver, 2002). Due to the nature of these clothing forms and the manner in which they are draped on the body, aligning designs to follow the lengthwise grain will disorient the designs and thereby make the designs unreadable, hence losing their meanings and essence. Other end uses are curtains, traditional 'kaba and slit', shirts, dresses etc.

\section{Fabric Width}

The standard fabric width of Texstyle Ghana Limited prints is $122 \mathrm{~cm}$ (48 inches). The company does not have any alternative printing machine that can provide wider widths and for that matter, a request in that direction will mean high capital investment. Akosombo Textile
Limited on the other hand has printing machines for wider widths, but they are made available on request by clients but not produced for the open market. Such widths are yet to be seen on the market. This makes the search of Akosombo Textile Limited and Texstyle Ghana Limited printed fabric with standard width in the Ghanaian market a difficult task and sometimes impossible.

\section{Packaging}

Fabrics from the local companies are packaged in yards of six and twelve for half piece and full piece respectively but not in bundle. This, according to the manufacturers, is the best convenient way of packaging the products since traditionally, six yards of fabric is used for 'Kaba and Slit' and ten to twelve yards for men's traditional cloth. This is due to the fact that, even though the fabrics are used for multipurpose, they basically find application in garment construction.

The tailors and dressmakers who were interviewed and later observed from the two major cities, ie. Accra and Kumasi revealed an interesting trend. Thirteen out of the 20respondents lay their fabrics regardless of the patterns presented in the fabrics. The priority is to cut the intended style and work within the fabric handed to them by the client. They are however, mindful of birds and parts of the human figure and the like, in a given fabric. Even that, they are only careful not to turn the objects upside down. The other seven, made up of four tailors and three dressmakers were concerned with patterns in the fabric and they try to align the patterns to create interesting effects but still have to work within the number of yards given to them by clients. For the seven, their major challenge had to do with motifs that follow the crosswise grain. In that regard, very little could be done depending on the nature of the design in the fabric and the style intended to be sewn. Further interactions clearly indicated that there was no avenue by which such difficulties pertaining to the use of the fabrics could be communicated to the manufacturers for redress. 
They can only hope to do their best to satisfy their clients and stay in business.

The designs shown in Fig. 1 to 6 are all African prints. It is very obvious that the prints have been designed to correspond to the width of the fabric and not the lengthwise grain of the fabric. Fabric width is 48inches $(122 \mathrm{~cm})$ for Texstyle Ghana Limited, whereas Akosombo Textile Limited had fabric width of 44 inches (112 $\mathrm{cm})$.

The designs in Fig. 1 to 3 are ideal for draping and suitable for men's cloth which does not necessitate cutting through the fabric. Constructing these fabrics into garments will necessitate cutting through the fabric which eventually distort the designs. The designs in Fig. 4 to
6 could however be cut and constructed into any garment without any distortion. These designs are considered all-ways designs and are very ideal for garment construction.

\section{DISCUSSION}

There exist a level of interdependency between the textiles and clothing industries all over the world and Ghanaian companies, in this regard, cannot take this for granted. Business operations keep changing day by day and the local industries cannot afford to stick to old practices. The global and competitive nature of today's market, create a great challenge for companies hoping to penetrate new markets to constantly revise their business operations to match up with the rapidly changing business operations worldwide. The textile-apparel industry is

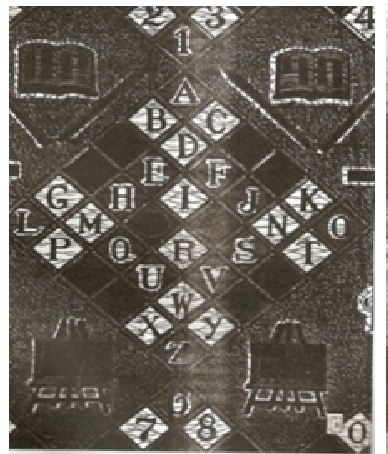

Fig. 1

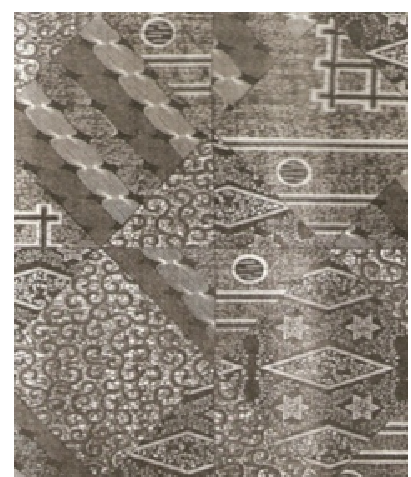

Fig. 4

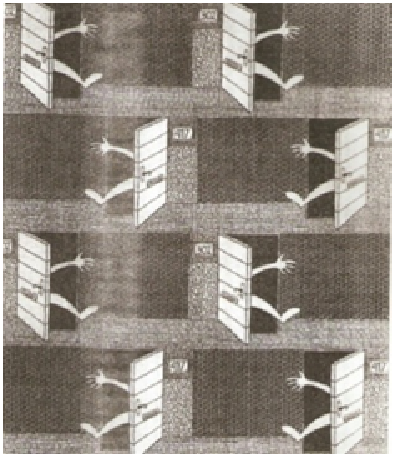

Fig. 2

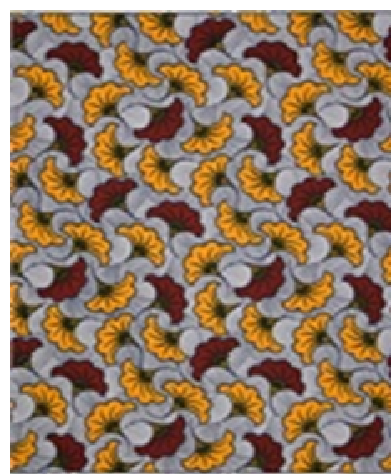

Fig. 5

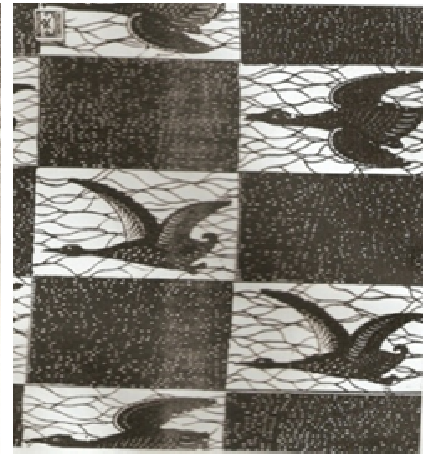

Fig. 3

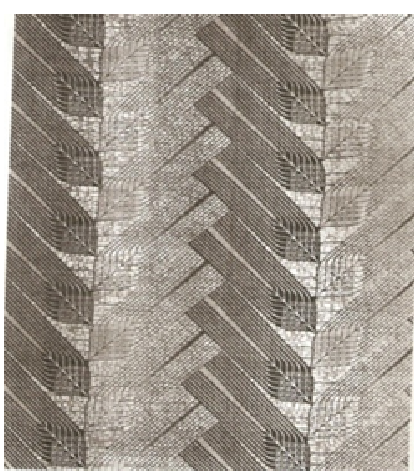

Fig. 6

Fig. 1,2,3,4,5 and 6: Samples of African prints observed 
Technical limitations of African prints and their implications ...

a pipeline consisting of interrelated activities aimed at bringing a product to the doorstep of the final consumer (Jones, 2006).

These activities start from the manufacture of fibre to the delivery of the final product (garment) to the consumer. In other words, there is a logical connection between the various processes or activities designed to convert an input into a product. In this sense, legally independent companies with a common goal can come together to manufacture products that satisfy consumer needs profitably. A meaningful co-operation can in no doubt yield mutual benefits. However, an antagonistic relationship could inhibit best practices and thereby contribute to lack of competitive edge.

In Ghana, the clothing or the fashion industry has fared differently and independently from the textile industry. On the world market, achieving a competitive advantage is crucial. A more co-ordinated approach would be a good course and in the right direction.

The pipeline has to do with fibre manufacture, fabric manufacture, apparel production and finally, distribution. These are the four major levels in the pipeline with other subsidiaries. However, technological changes and the need to achieve competitive advantage have contributed to the blurring of these levels. Fibre manufacturers are diverting into fabric and garment manufacture and also distributing the products to the markets, a vertical integration approach.

To be able to cope with the speed of delivery in today's marketplace, one cannot afford to be less concerned with activities that have to do with related industries. The possibility of diverting into other levels or such collaborations that are geared towards providing the right products, at the right time to the right consumer at the right place cannot be ignored. It must be noted that these levels could be geographically dispersed across national boundaries; the most important factor is the level of co-ordination and interactions that exist between the partners.
For the Ghanaian clothing industry to compete successfully on both local and more importantly, the international scene, using locally produced fabric will demand some level of collaboration with the textile industries. Requirements of the clothing industry could be factored into the design and production activities of the textile industry so that fabrics produced could address the technical factors discussed earlier. Feedbacks from the clothing industry in this direction are therefore critical to the successful design and production of fabrics which are the main raw materials for the clothing industry, and cannot be taken for granted.

It is surprising to note that the clothing and textile industries in Ghana have no such interactions aimed at providing useful information for the production processes and this is detrimental to both industries. With this, it becomes difficult to go beyond the African market since majority of the fabrics produced (especially wax) have some deficiencies that make them unmarketable in other markets. In the same vein, since clothing producers in Ghana use the fabrics from the Ghanaian textile mills, coupled with the fact that majority of these clothing producers also ignore these technical considerations, it will be difficult for them to market their products outside the African market and even if they do, the price will be much higher (aside other factors that go into pricing), considering the shorter width of fabrics they have to work with.

\section{CONCLUSION}

Ironically, interactions with the designers in these two industries (clothing and textiles) reveal that none of the parties give or receive feedbacks from each other, a scenario that does not create a better platform for product development. As evident in the findings, very few clothing manufacturers are aware of the technical considerations discussed. This coupled with the fact that print designers have very little or no knowledge in this regard, very little can be done to improve upon what is already in the market. This is why effective collaboration is 
important to address these issues. With the current condition of dumped fabrics on the Ghanaian market from Asia and other continents, coupled with the fact that they come in low prices as compared to the locally produced fabrics, penetrating into international markets especially, Europe and America will not be a bad idea. But before this is ventured, the textile companies would have to address the technical considerations in garment making in other to compete favourably with other competitors.

The local fashion industry, to a large extent, depends on foreign textiles due to their standard width, fabric variety, wider range of designs and colour ways, which offer designers the opportunities to utilize them for a wider application as compared to the local prints which have limited application. However, with the move of the government to revive the textiles and garments sub-sector, a strong linkage between the two industries is very crucial. This will create a platform for the textile companies to produce to meet the standards and requirements of the fashion industry in order to give them competitive edge to penetrate the international market.

Apparel and Textile product developers must constantly redefine what they produce, how they produce it, and how they market and distribute it to customers, thereby translating into opportunities (Keiser \& Garner, 2008). Textile companies will have to react quickly and flexibly to the latest fashion. This could be achieved by:

- Aligning prints to follow the lengthwise grain. Aside printing designs that follow the lengthwise grain for clients on request, the companies must themselves start applying it to their own designs made for the mass market.

- Programming designs to give optical impression of how motifs look on a scanned model especially with one-way direction motif layout.
- A 3-dimensional display of a model draped with a fabric design will give the designer a real impression of how the fabric will work for the garment manufacturer. This helps the garment manufacturer to correct any limitations that may hinder the fast manufacture of garments to meet real time needs.

- Designing fabrics in accordance with the behaviour of the fabric to be printed on and to meet the functional requirements of the garment manufacturer.

- Creating a strong linkage between fabric design and garment construction; an eminent possibility in the future by liaising with garment manufacturers or employing personnel with in-depth knowledge and skill in both fields to provide technical advice on best practices.

- With regards to fabric width, Ghanaian textile companies who do not have machines to accommodate wider widths can partner with other fabric manufacturing companies employing the Quick Response strategy. The Quick Response Strategy aims at fostering association, trust and communication among manufacturers, suppliers and retailers and through Electronic Data Interchange (EDI), the companies are able to do business irrespective of their geographical locations.

- With respect to packaging and presentation, fabrics could be designed according to their end use suitability so that fabrics that are intended for traditional clothing that require little or no cutting are made differently from those intended for high fashionable garments that necessitate thorough drafting and cutting processes. Marketing of these products could be done to highlight the differences and the public educated on the differences in the products and their applications to facilitate purchasing and appropriate use of the products. 


\section{REFERENCES}

Fabric Width (2009). Retrieved on the 11th November, 2009 from http:// www.fashiondex.com/howos/htstfm4.php.

Jenkyn, J. S. (2005), Fashion Design, 2nd Edition. Laurence King Publishing, London.

Jones, R. M. (2006). The Apparel Industry. Second Edition. UK: Blackwell Publishing Ltd,

Keiser, S. J. and Garner, M. B. (2008). Beyond Design - The synergy of Apparel product development, Second Edition. Fairchild Publications Inc. USA.

Laver, J. (2002). Costume and Fashion - A concise History. Fourth Edition. Thames and Hudson Ltd, London.

Orhin, I. G. (2007). The Changing Face of the textile Industry. Public Agenda. Retrieved June 29, 2007 from http://www. al1Africa.com

Osei-Bonsu, V. (2001). Promoting Made in Ghana Textiles. Unpublished BA Thesis, College of Art, Textiles Section.

Tatham, C. and Seaman, J. (2003). Fashion Design Drawing Course; Principle, Practice and Technique. The ultimate guide for the aspiring fashion artist. Thames and Hudson Ltd, London.

Vlisco (2011). Guaranteed Real Dutch Wax Block Print. Retrieved on the $7^{\text {th }}$ May, 2011 from http://www.vlisco.com

WTO(2004). Report on Agreement on Textiles and Clothing (ATC). Retrieved on the 20th June, 2009 from http://www.wto.org 